\title{
Serum testosterone levels in type 2 diabetes mellitus
}

\author{
Kundu D. ${ }^{1}$, Ghosh E. ${ }^{2}$, Roy S.S. ${ }^{3}$, Basu S. ${ }^{4}$ \\ ${ }^{1}$ Dr. Dipankar Kundu, Associate Professor, Department of Biochemistry, Medical College, Kolkata, India, ${ }^{2}$ Dr. Enakshi \\ Ghosh, Assistant Professor, Department of Anatomy, RG Kar Medical College, Kolkata, India, ${ }^{3}$ Dr. Suparna Sinha Roy \\ (PGT), Department of Biochemistry, Medical College, Kolkata, India, ${ }^{4}$ Dr. Satyaki Basu (PGT), Department of \\ Biochemistry, Medical College, Kolkata, India.
}

Corresponding Author: Dr. Enakshi Ghosh, Assistant Professor, Department of Anatomy, RG Kar Medical College, Kolkata, India. E-mail: drenakshighosh@gmail.com

\begin{abstract}
Introduction: Diabetes mellitus is a multifactorial disease which is characterised by hyperglycaemia, dyslipidaemia, involves various organ systems, and results in various long-term complications. Several studies have suggested that men with low testosterone levels are at a greater risk of developing type 2 diabetes mellitus, and that low testosterone levels may even predict the onset of diabetes. Recent studies have shown that a low serum testosterone level is strongly associated with an increased likelihood of the metabolic syndrome. Aim: To compare the serum total testosterone levels in type 2 diabetes mellitus patients with that of non-diabetic healthy controls. Material and Methods: The study was conducted in OPD of Medical College, Kolkata. In the present study 50 men aged 35-55 years who were diagnosed as type 2 diabetes mellitus patients and confirmed by the estimation of fasting plasma glucose ( $\geq 126 \mathrm{mg} / \mathrm{dl})$, post prandial blood glucose $(\geq 200 \mathrm{mg} / \mathrm{dl})$ and $\mathrm{HbA}_{1 \mathrm{C}}(\geq 6.5 \%)$ were selected, 50 healthy age and BMI matched individuals, were selected as controls. Patients with a known history of hypogonadism, panhypopituitarism, hyperthyroidism, patients taking exogenous testosterone and glucocorticoids, patients suffering from chronic debilitating disease, such as renal failure, cardiac failure, liver cirrhosis, or HIV, were excluded from the study. The laboratory investigations included evaluation of serum testosterone levels, fasting and postprandial blood glucose, with the levels of $\mathrm{HbA}_{1 \mathrm{c}}$ and Creatinine. Statistical analysis was performed using SPSS 20.0. Results are represented as mean \pm SD and number (\%). Pearson's correlation test was performed to measure the linear dependence of the study parameters. Results: Serum Total Testosterone level of diabetic group was $3.51 \pm 1.26 \mathrm{ng} / \mathrm{ml}$, which was found significantly lower than control group with serum total testosterone level $5.88 \pm 2.34 \mathrm{ng} / \mathrm{ml}$, (p-value $<0.0001$ ). Conclusion: This study has shown that there is a significant reduction in serum total testosterone levels in type 2 diabetes mellitus patients.
\end{abstract}

Key words: Diabetes mellitus, low testosterone, insulin resistance, hyperglycemia

\section{Introduction}

Diabetes mellitus is a multifactorial disease which is characterised by hyperglycaemia, dyslipidaemia, involves various organ systems, and results in various long-term complications. Several studies have suggested that men with low testosterone levels are at a greater risk of developing type 2 diabetes mellitus, and that low testosterone levels may even predict the onset of diabetes $[1,2,3]$.

Testosterone, a steroidal hormone from androgen group, secreted into the circulation by Leydig cells of testicles, plays an important part in various biological functions

Manuscript received: $26^{\text {th }}$ October 2018

Reviewed: $4^{\text {th }}$ November 2018

Author Corrected: $10^{\text {th }}$ November 2018

Accepted for Publication: $16^{\text {th }}$ November 2018 during the course of male life. Numerous studies have also identified inverse relationship between serum testosterone, insulin resistance and hyperglycemia. As Diabetes Mellitus and Testosterone hormone dysfunction are two common endocrinopathies, both may be associated with insulin resistance and defective metabolism, there seems to be some significant relation between these two and they may have tend to mutually influence each other.

Various mechanisms by which low serum testosterone may be considered a threat for type 2 Diabetes Mellitus and metabolic syndrome include changes in the body composition, androgen receptor polymorphisms, glucose transport and decreased antioxidant effects. On 


\section{Original Research Article}

the other hand, diabetes mellitus may also be considered a risk factor for hypogonadism through visceral obesity, reduced Sex Hormone Binding Globulin (SHBG), inhibition of gonadotrops secretion or production of testosterone by Leydig cells, cytokines mediated inhibition (e.g. TNF $\alpha$, IL-1 $\beta$, IL-6) of steroid production and increased aromatase activity resulting in estrogen excess [4]. Recent studies have shown that a low serum testosterone level is strongly associated with an increased likelihood of the metabolic syndrome (MES) in both Caucasian and Asian men [5, 6].

Hence, this study has been carried out to find out the association involving serum Total Testosterone and type 2 Diabetes Mellitus and to determine whether it should be considered as a diagnostic \& prognostic marker of Diabetes Mellitus.

\section{Aim}

To compare the serum total testosterone levels in type 2 diabetes mellitus patients with that of non-diabetic healthy controls.

\section{Material and Methods}

The study was conducted in Medical College, Kolkata, during the period 2016 - 2018 after obtaining ethical clearance. In the present study 50 men aged 35-55 years who were diagnosed as type 2 diabetes mellitus patients and confirmed by the estimation of fasting plasma glucose $(\geq 126 \mathrm{mg} / \mathrm{dl})$, post prandial blood glucose $(\geq 200 \mathrm{mg} / \mathrm{dl})$ and $\mathrm{HbA}_{1 \mathrm{C}}(\geq 6.5 \%)$ were selected from the OPD of Medical College Kolkata were included in the study as cases, 50 healthy age and BMI matched individuals, were selected as controls.

Exclusion Criteria: Patients with a known history of hypogonadism, panhypopituitarism, hyperthyroidism, patients taking exogenous testosterone and glucocorticoids, patients suffering from chronic debilitating disease, such as renal failure, cardiac failure, liver cirrhosis, or HIV, were excluded from the study. The mean level of serum testosterone was calculated in various age and BMI groups and compared with controls. Information on demographic data, personal history and history of present illness, and other co-morbid conditions were collected followed by the clinical and systematic examination of all the patients.

The laboratory investigations included evaluation of serum testosterone levels, blood glucose levels (fasting blood glucose and postprandial plasma glucose), with the levels of $\mathrm{HbA} 1 \mathrm{c}$ and creatinine. Five $\mathrm{ml}$ venous sample was obtained from left median cubital vein after an overnight fast of 8-12 hours from the participants under aseptic conditions. Centrifugation of the blood was done at $4000 \mathrm{rpm}$ for 5 minutes for separation of plasma. Analysis of Fasting plasma glucose (FPG) was done on fresh plasma. Serum was frozen at $-30^{\circ} \mathrm{C}$ for estimation of serum testosterone, creatinine levels. Two millilitre of whole blood was collected in Ethylenediamine tetra acetic acid (EDTA) containers for analysis of HbA1c.

Chemistry auto-analyzer Kone Lab was used to measure FBG. Fully automated hormone analyzer, Advia Centaur, based on the principle of chemiluminescence immunoassay technique was used to measure serum testosterone. Immuno-inhibition method was used to estimate $\mathrm{HbA} 1 \mathrm{c}$ levels.

Statistical analysis- Statistical analysis was performed using SPSS 20.0. Results on continuous and categorical measurements are represented as mean \pm SD and number (\%). Pearson's correlation test was performed to measure the linear dependence of the study parameters.

Significance between the study parameters was determined by Chi-square/Fisher exact test and student t-test. $\mathrm{P}<0.05$ is considered statistically significant.

\section{Results}

The association between mean ages in both the groups was not significant $(\mathrm{P}=0.713$; Table 1$)$. The diabetic patients age group was found to be $45.89 \pm 6.47$ years while that of control group patients was found to be $44.88 \pm 7.12 y e a r s$, which was not significantly different ( $\mathrm{p}=0.713$ ). BMI of diabetic group was $25.98 \pm 2.62 \mathrm{~kg} / \mathrm{m} 2$, which was significantly higher than that of control group with BMI $24.08 \pm 3.18 \mathrm{~kg} / \mathrm{m} 2$ (p-value= 0.021$)$.

FBG of diabetic group was $145 \pm 32 \mathrm{mg} / \mathrm{dl}$, which was statistically higher than control group with FBG $94 \pm 11 \mathrm{mg} / \mathrm{dl}$ (pvalue $<0.05$ ). Similarly, PPBG of diabetic group was $254 \pm 37 \mathrm{mg} / \mathrm{dl}$, which was statistically higher than control group with PPBG $128 \pm 29 \mathrm{mg} / \mathrm{dl}$ (p-value $<0.05)$.

The HbA1c in diabetic group was $9.61 \pm 2.29 \%$, which was significantly higher as compared to non-diabetic individuals with $\mathrm{HbA}_{1 \mathrm{c}} 4.49 \pm 0.86 \%$ (p- value = 0.0001). 
Serum Total Testosterone level of diabetic group was $3.51 \pm 1.26 \mathrm{ng} / \mathrm{ml}$, which was found significantly lower than control group with serum total testosterone level $5.88 \pm 2.34 \mathrm{ng} / \mathrm{ml}$, (p-value $<0.0001$ ).

Serum Creatinine level of diabetic group was $1.29 \pm 0.71 \mathrm{mg} / \mathrm{dl}$, which was found significantly lower than control group with serum total testosterone level $0.98 \pm 0.31 \mathrm{mg} / \mathrm{dl}$, (p-value $=0.0024)$.

Table-1: Comparison of various measured parameters between study groups by Student's $t$ test.

\begin{tabular}{|c|c|c|c|c|}
\hline Sl. No. & Parameters & Cases \pm SD & $\begin{array}{c}\text { Control } \\
\pm \text { SD }\end{array}$ & p Value \\
\hline 1 & Age(years) & $45.89 \pm 6.47$ & $44.88 \pm 7.12$ & 0.713 \\
\hline 2 & BMI (kg/m2) & $25.98 \pm 2.62$ & $24.08 \pm 3.18$ & 0.021 \\
\hline 3 & FBG $(\mathrm{mg} / \mathrm{dl})$ & $145 \pm 32$ & $94 \pm 11$ & $<0.05$ \\
\hline 4 & PPBG $(\mathrm{mg} / \mathrm{dl})$ & $254 \pm 37$ & $128 \pm 29$ & $<0.05$ \\
\hline 5 & HBA $_{1 C}(\%)$ & $9.61 \pm 2.29$ & $4.49 \pm 0.86$ & 0.0001 \\
\hline 6 & Total Testosterone $(\mathrm{ng} / \mathrm{ml})$ & $3.51 \pm 1.26$ & $5.88 \pm 2.34$ & $<0.0001$ \\
\hline 7 & Serum Creatinine $(\mathrm{mg} / \mathrm{dl})$ & $1.29 \pm 0.71$ & $0.98 \pm 0.31$ & 0.0024 \\
\hline
\end{tabular}

Table-2: Correlation of testosterone level with biochemical parameters

\begin{tabular}{|c|c|c|c|c|}
\hline Variables & HbAlc & $\begin{array}{c}\text { Fasting blood glucose } \\
(\mathrm{mg} / \mathrm{dl})\end{array}$ & $\begin{array}{c}\text { Postprandial blood } \\
\text { glucose }(\mathrm{mg} / \mathrm{dl})\end{array}$ & BMI $(\mathrm{kg} / \mathrm{m} 2)$ \\
\hline $\begin{array}{c}\text { Testosterone } \\
(\mathrm{ng} / \mathrm{dl})\end{array}$ & -0.3641 & -0.4319 & -0.4198 & -0.3618 \\
\hline
\end{tabular}

Negative correlation was observed between serum testosterone levels and biochemical parameters such as BMI $(\mathrm{r}=-0.3618 ; \mathrm{P}=0.0013)$, HbA1c $(\mathrm{r}=-0.3641 ; \mathrm{P}=0.0015)$, fasting blood glucose $(\mathrm{r}=-0.4319 ; \mathrm{P}=0.0001)$, and postprandial plasma glucose $(\mathrm{r}=-0.4198 ; \mathrm{P}=0.0002)$.

\section{Discussion}

Main objective of our study was to compare serum total testosterone levels of type 2 Diabetes mellitus patients with non-diabetic control group. Testosterone is the most important gonadal hormone that regulates the physiological functions of the body. Interestingly, in the present study, we have found that serum testosterone level of diabetic group was significantly lower than that in non diabetic control group ( $\mathrm{p}$-value $<0.0001$ ).

The mean of serum testosterone of diabetic group was found $3.51 \pm 1.26 \mathrm{ng} / \mathrm{ml}$ and serum testosterone of nondiabetic control group was $5.88 \pm 2.34 \mathrm{ng} / \mathrm{ml}$, as shown in [Table-1]. Therefore, we concluded that the lower serum testosterone levels were found in patients of type 2 diabetes mellitus when compared with non-diabetic control. Moreover, in our study, out of 50 diabetic patients, 23 patients i.e. about $46 \%$ had lower level of serum total testosterone $(<3 \mathrm{ng} / \mathrm{ml})$.

Similar are the findings of Yeap et al., in which they have shown that diabetic men were found to have around two time's lower testosterone levels as compared to men without diabetes mellitus [7]. Ding et al. conducted a meta-analysis which included 3825 men and confirmed that there was higher prevalence of lower level of serum testosterone in type 2 Diabetic men [8]. $\mathrm{Oh}$ et al. Also showed a reciprocal relationship between serum total testosterone and type 2 diabetes mellitus [9]. Corona et al. conducted more recent meta-analysis including 1822 diabetic men and 10009 non diabetic controls and have found that serum total testosterone level was lower in men with diabetes mellitus than nondiabetic controls (mean difference, $2.99 \mathrm{nmol} /$ litre) [10].

Kupelian et al. conducted a study and suggested that low testosterone may be a marker in association of type 2 diabetes mellitus with insulin resistance [11]. Besides this several other evidences have also been given showing the role of lower testosterone in insulin resistance. Yialamas et al. have suggested in their study that testosterone may affect insulin resistance through changes in body composition and may also regulate insulin sensitivity [12]. Low levels of testosterone have been reported to be associated with type II diabetes and insulin resistance [13]. The decrease in hormone level is 


\section{Original Research Article}

slow and constant over all decades and starts early in life, probably after the third or fourth decade. The exact cause of the age-related reduction in testosterone levels is not known. Evaluation of fasting blood glucose and postprandial blood glucose levels in normal and diabetic patients in the present study revealed significantly higher blood glucose levels in the diabetic patients.

The correlation between the blood glucose level and serum testosterone was found to be significant and negatively correlated, indicating improvement in blood glucose levels with increase in serum testosterone. Studies have reported inverse relationship between blood glucose and testosterone [14].

The treatment of hypogonadism by means of testosterone replacement therapy often leads to reduction in blood glucose level along with reduction in the resistance to insulin among the diabetic patients [15]. Present study revealed significant correlation between BMI and serum testosterone.

Testosterone level was reduced in diabetic patients with increased BMI. Similar results were reported by Aftab et al [16] and Dhindsa et al [17], demonstrating significant association between BMI and low serum testosterone level. Serum testosterone treatments have also been reported to impact the HbAlc levels in diabetic patients [18].

Several contrary reports have been published with respect to the correlation between serum testosterone and HbA1c levels. Dhindsa et al [17] Grossmann et al [19] and Al Hayek et al [13] reported no significant correlation between $\mathrm{HbA} 1 \mathrm{c}$ and testosterone levels, which is in contrast with those by Kapoor et al [20] in which testosterone level correlated positively with HbA1c level. On the other hand, a study on Japanese men revealed negative association between testosterone level and HbA1c, possibly due to decrease in stimulatory effect of testosterone on red blood synthesis [21].

\section{Conclusion}

This study has shown that there is a significant reduction in serum total testosterone levels in type 2 diabetes mellitus patients. Low testosterone level can be one of the predictive markers for determining insulin resistance and other metabolic conditions.

This may highlight requirement of urgent implementation of screening programs, in order to detect testosterone deficiency in all type 2 diabetes mellitus male patients at an early stage and to supplement testosterone accordingly. Testosterone administration may; however, help in treating the conditions by decreasing resistance to insulin, increasing iron absorption, and reducing BMI.

Further research with a considerably larger population and other clinical parameters may aid in establishing testosterone level as a marker in early diagnosis and treatment. Future clinical trials should first compare or combine testosterone therapy with lifestyle measures and/or insulin-sensitizing agents; second, target men with lower testosterone, larger amounts of visceral fat, and more pronounced insulin resistance; and third, be powered to address clinically important endpoints and thus inform about the risk-benefit ratio of testosterone therapy. Unless and until a definitive randomized Control trials eventuates, information from future trials can be improved by standardized, prospective endpoints facilitating future meta-analyses.

\section{Funding: Nil, Conflict of interest: None Permission of IRB: Yes}

\section{References}

1. Haffner SM, Miettinen H, Karhapää P, et al. Leptin concentrations, sex hormones, and cortisol in nondiabetic men. J Clin Endocrinol Metab. 1997 Jun;82 (6): 1807-9.

2. Shores MM, Matsumoto AM, Sloan KL, et al. Low serum testosterone and mortality in male veterans. Arch Intern Med. 2006 Aug 14-28;166(15):1660-5.

3. Selvin E, Feinleib M, Zhang L, et al. Androgens and diabetes in men: results from the Third National Health and Nutrition Examination Survey (NHANES III). Diabetes Care. 2007 Feb;30(2):234-8.

4. Kalyani RR, Dobs AS. Androgen deficiency, diabetes and the metabolic syndrome in men. Curr Opin Endocrinol Diabetes Obes; 2007; Vol. 14; 226-234.

5. Li C, Ford ES, Li B, et al. Association of testosterone and sex hormone-binding globulin with metabolic syndrome and insulin resistance in men. Diabetes Care. 2010 Jul;33(7):1618-24. doi: 10.2337/dc09-1788. Epub 2010 Apr 5.

6. Tong PC, Ho CS, Yeung VT, et al. Association of testosterone, insulin-like growth factor-I, and C-reactive protein with metabolic syndrome in Chinese middleaged men with a family history of type 2 diabetes. J Clin Endocrinol Metab. 2005 Dec;90(12):6418-23. Epub 2005 Sep 27. 


\section{Original Research Article}

7. Yeap BB, Alfonso H, Chubb SA, et al. Reference ranges and determinants of testosterone, dihydrotestosterone, and estradiol levels measured using liquid chromatography-tandem mass spectrometry in a population-based cohort of older men. J Clin Endocrinol Metab. 2012 Nov; 97(11):4030-9. doi: 10.1210/jc.20122265. Epub 2012 Sep 13.

8. Ding EL, Song Y, Malik VS, et al. Sex differences of endogenous sex hormones and risk of type 2 diabetes: a systematic review and meta-analysis. JAMA. 2006 Mar 15; 295(11):1288-99.

9. Oh JY, Barrett-Connor E, Wedick NM, et al. Endogenous sex hormones and the development of type 2 diabetes in older men and women: the Rancho Bernardo study. Diabetes Care. 2002 Jan;25(1):55-60.

10. Corona G, Monami M, Rastrelli G, et al. Type 2 diabetes mellitus and testosterone: a meta-analysis study. Int J Androl. 2011 Dec;34(6 Pt 1):528-40. doi: 10.1111/j.1365-2605.2010.01117.x. Epub 2010 Oct 24.

11. Kupelian V, Page ST, Araujo AB, et al. Low sex hormone-binding globulin, total testosterone, and symptomatic androgen deficiency are associated with development of the metabolic syndrome in nonobese men. J Clin Endocrinol Metab. 2006 Mar;91(3):843-50. Epub 2006 Jan 4. DOI:10.1210/jc.2005-1326

12. Yialamas MA, Dwyer AA, et al. Acute sex steroid withdrawal reduces insulin sensitivity in healthy men with idiopathic hypogonadotropic hypogonadism. Journal of Clinical Endocrinology and Metabolism; 2007; Rev. 92; 4254-4259.

13. Al Hayek A, Ajlouni K, Khader Y, Jafal S, Khawaja $\mathrm{N}$, Robert A. Prevalence of low testosterone levels in men with type 2 diabetes mellitus: a cross-sectional study. J Family Community Med 2013; 20(3):179-186.

14. Pitteloud N, Mootha VK, Dwyer AA, et al. Relationship between testosterone levels, insulin sensitivity, and mitochondrial function in men. Diabetes Care. 2005 Jul;28(7):1636-42.

15. Basu AK, Singhania P, Bandyopadhyay R, et al. Late onset hypogonadism in type 2 diabetic and nondiabetic male: a comparative study. J Indian Med Assoc. 2012 Aug;110(8):573-5.

16. Saboor Aftab SA, Kumar S, Barber TM. The role of obesity and type 2 diabetes mellitus in the development of male obesity-associated secondary hypogonadism. Clin Endocrinol (Oxf). 2013 Mar;78(3):330-7. doi: 10. $1111 /$ cen. 12092 .

17. Dhindsa S, Prabhakar S, Sethi M, et al. Frequent occurrence of hypogonadotropic hypogonadism in type 2 diabetes. J Clin Endocrinol Metab. 2004 Nov;89(11): 5462-8. DOI:10.1210/jc.2004-0804

18. Hackett G, Cole N, Bhartia M, Testosterone replacement therapy improves metabolic parameters in hypogonadal men with type 2 diabetes but not in men with coexisting depression: the BLAST study. J Sex Med. 2014 Mar;11(3):840-56. doi: 10.1111/jsm.12404. Epub 2013 Dec 6.

19. Grossmann M, Thomas MC, Panagiotopoulos S, et al. Low testosterone levels are common and associated with insulin resistance in men with diabetes. J Clin Endocrinol Metab. 2008 May; 93(5):1834-40. doi: 10. 1210/jc.2007-2177. Epub 2008 Mar 4.

20. Kapoor D, Aldred H, Clark S, et al. Clinical and biochemical assessment of hypogonadism in men with type 2 diabetes: correlations with bioavailable testosterone and visceral adiposity. Diabetes Care. 2007 Apr;30 (4):911-7.

21. Cheung KK, Luk AO, So WY, et al. Testosterone level in men with type 2 diabetes mellitus and related metabolic effects: A review of current evidence. J Diabetes Investig. 2015 Mar;6(2):112-23. doi: 10.1111/ jdi.12288. Epub 2014 Nov 3.

\section{How to cite this article?}

Kundu D, Ghosh E, Roy S.S, Basu S.Serum testosterone levels in type 2 diabetes mellitus. Int J Med Res Rev 2018; 6(08): 409-413. doi:10.17511/ijmrr.2018.i08.03. 